\title{
PENGELOLAAN SEKOLAH BERBASIS FILANTROPI (Studi Situs di SMK Gratis Smart Informatika Surakarta)
}

\author{
Joko Subando
}

STAI Mamba’ul 'Ulum Surakarta

The purpose of this study is to describe the management of school-based philanthropy on SMK Gratis Smart Informatika Surakarta.

The study used a qualitative approach to the design of ethnography. Data were collected through observation, documentation and in-depth interviews with a variety of sources, Solopeduli Foundation, Principal, Vice Principal, Teachers, Employees, Students and Parents Students. The information collected is around management of schools ranging from school strategic plans, operational plans, school programs, fund management, human resources, learning management, monitoring, evaluation, and so forth. The data has been collected and then analyzed with a model Miles-Hubberman.

The results showed that the presence of Solopeduli foundation as Islamic philanthropic institutions to make the school as a unit management program has a distinctive character that sharia management. Poverty, sincerity and concern used as view point institutions in organizing employees, equalizing step, build unity and establish sincerity in work. Donors, donations, and the mandate of the donors is said lighter so that raises self control and supervision of the divine. This is what makes the activities run effectively and efisient. School explore alms, Tahfidz, mentoring and make it as an entry point to build and deliver school Spiritual intelligence to the summit of achievement.

Keyword: management, schools, philanthropy 


\section{A. Pendahuluan}

Pemerintah Provinsi Jawa Tengah telah menerbitkan peraturan Daerah (Perda) nomor 5 tahun 2014 tentang Rencana Pembangunan Jangka Menengah Daerah 2013-2018. Di dalam perda tersebut terlihat grafik perkembangan pendidikan selama kurun 5 tahun terakhir dan rencana pendidikan 5 tahun yang akan datang.

Menurut data Jawa Tengah dalam angka (2013), jumlah penduduk usia 7 sampai 12 di tahun 2012 sebanyak 3.645.929 orang. Sementara jumlah penduduk usia 13 sampai 15 tahun sebanyak 1.756.919 orang. Jumlah SD/MI 23.358 sekolah dan untuk jumlah SMP/MTS tahun 2012 sebanyak 4.679 unit sekolah.

Angka partisipasi sekolah (APS) penduduk usia 7-12 tahun mengalami peningkatan mulai dari $98.83 \%$ di tahun 2008 menjadi $98.87 \%$ di tahun 2012. Untuk usia 13-15 tahun meningkat dari 84.275 di tahun 2008 menjadi $89.59 \%$ di tahun 2012. Secara nasional angka partisipasi sekolah di tingkat nasional Jawa Tengah menduduki peringkat ke empat setelah Banten, Jawa Barat dan DKI Jakarta. Lebih jauh, menurut data Dinas pendidikan provinsi Jawa Tengah tahun 2012 APS siswa SD/MI/SDLB sebesar 0,12, APS siswa SMP/Mts sebesar 0,38 dan APS siswa SMA/SMK/MA sebesar 0,08. Jadi angka putus sekolah paling tinggi di tingkat SMP/MTs.

Banyak faktor yang menyebabkan siswa SMP/Mts tidak melanjutkan ke jenjang pendidikan yang lebih tinggi yaitu setingkat SMA/SMK/MA. Ada faktor internal seperti motivasi diri dan faktor eksternal seperti keterbatasan ekonomi, sosial budaya dan faktor geografis. Menurut riset yang dilakukan Resi Anggun Sutiasnah dan Mutiara Farah (2015), ekonomi keluarga menjadi factor dominan anak tidak melanjutkan sekolah atau putus sekolah.

Ketidakmampuan anak melanjutkan sekolah karena beaya sekolah yang tinggi. Sebagai gambaran, ada empat sekolah SMA di Indonesia yang sering mendapatkan sebutan sekolah mahal, yaitu:

\section{1. SMA Pelita Harapan Lippo Cikarang}

SMA Pelita Harapan Lippo Cikarang berbeda dari sekolah bertaraf internasional yang banyak dikembangkan belakangan ini. SMA Pelita Harapan Lippo Cikarang memiliki kurikulum internasional bernama International Baccalaureate. SMA Pelita Harapan Lippo Cikarang membanderol biaya sekolah sebesar USD 9.000 per tahun. Biaya yang harus dibayarkan dalam mata uang dolar Amerika itu mencakup biaya kegiatan ekstrakurikuler, komputer, buku, dan lain-lain.

\section{2. SMA Ciputra Surabaya}

SMA Ciputra Surabaya yang didirikan pada tahun 1996 ini juga menerapkan kurikulum International Baccalaureate, sama seperti SMA Pelita Harapan Cikarang. SMA Ciputra Surabaya membanderol biaya pembangunan sebesar 40 juta rupiah dan SPP sebesar 4 juta rupiah per bulan.

3. 3. SMA Global Jaya International School Tangerang Selatan 
SMA Global Jaya International School Tangerang Selatan yang didirikan pada tahun 1998 ini memiliki 47 jenis kegiatan ekstrakurikuler. Setelah diterima di SMA GJIS Tangerang Selatan, siswa-siswa itu dikenai biaya SPP sebesar 5 juta rupiah per bulan dan uang pangkal sebesar 15 juta rupiah.

\section{4. SMA Terpadu Krida Nusantara Bandung}

SMA Terpadu Krida Nusantara Bandung diresmikan pada tahun 1996 dan menempati lahan seluas 27 hektare di lembah Bukit Manglayang, Cibiru, Bandung. Biaya pendidikan di SMA Terpadu Krida Nusantara ini mencakup uang pangkal sebesar 30 juta rupiah, biaya pakaian seragam sebesar 2,4 juta rupiah, biaya SPP sebesar 2,6 juta rupiah per bulan, dan biaya cuci pakaian sebesar 600 ribu rupiah per semester.

Namun ironisnya peraih prestasi tertinggi Ujian Nasional (UN) 2015 bukanlah dari sekolah sekolah di atas. Menurut Jakarta bisnis.com perih nilai tertinggi UN berasal dari Bogor. Ketiga pelajar yang meraih nilai UN tertinggi di Kota Bogor yaitu Fikry Nurrahman (SMAN 1 Bogor) peraih nilai UN tertinggi IPS; Faridh Afdhal Aziz (SMAN 1 Bogor) peraih nilai UN tertinggi IPA; dan Denisa Desri Fauziah (SMAKBO) peraih nilai UN SMK tertinggi.

Di Surakarta sendiri peraih prestasi UN bukanlah berasal dari sekolah sekolah berbeaya tinggi bahkan justru berasal dari sekolah gratis. SMK Smart Informatika Surakarta pemegang peringkat pertama rata-rata nilai Ujian Nasional (UN) 2015 tertinggi se-Surakarta untuk jenjang SMK dari 50 SMK negeri dan swasta.

SMK SMART INFORMATIKA merupakan sekolah menengah Teknologi Informasi dan Komunikasi yang ditujukan untuk menampung anak yatim/dhuafa. Kualifikasi output dari SMK ini adalah hafal 5 jus Al-Quran, hafal hadist Arbain nabawi, Memiliki kepribadian yang utuh, mampu berkomunikasi dengan bahasa Inggris dan bahasa Arab dan lain lain. Sekolah tersebut menarik untuk dikaji sebab di tahun 2015 ini menjadi sekolah fenomenal dengan predikat sekolah baru namun langsung menghasilkan lulusan yang cukup bagus.

\section{B. Pembahasan}

Istilah filantropi belum begitu memasyarakat di kalangan umat saat ini, walaupun keberadaan lembaga tersebut sudah ada sejak zaman yunani kuno. Latar belakang munculnya lembaga ini karena ketidakmampuan negara memenuhi kebutuhan dasar warga negara seperti kebutuhan di bidang pendidikan, kesehatan, ekonomi dan lain sebagainya. Atau ketidakmauan pemerintah untuk menyentuh wilayah wilayah tersebut, hingga akhirnya bermunculanlah lembaga lembaga filantropi. Jadi lembaga ini mengurusi area kosong yang tidak disentuh oleh negara atau disetuh negara namun tidak optimal.

Filantropi merupakan wujud kedermawanan social masyarakat dari kalangan ekonomi kuat atas masyarakat ekonomi lemah atau masyarakat miskin. (Imron Hadi Tami, 2011 dan Aan Nasrulah, 2015). Namun hubungan keduanya bukanlah antara superior dengan inferior namun atas dasar kemanusian. Spirit yang muncul benar benar karena dorongan spiritual bukan karena material. Dorongan spiritual inilah yang akhirnya menjadikan lembaga filantropi memiliki 
karakter manajemen yang berbeda dengan lembaga profit lainnya. Manajemen ini bukan berarti mewajibkan lembaga filantropi untuk selalu rugi ketika membuka unit usaha namun kedermawanan diletakkan pada dasar lembaga yang paling mendasar. Semangat membantu dan menolong menjadi filosofi utama dalam setiap program. Orientasi manajemen yang tidak hanya sekedar meraih profit semata namun juga orientasi keberkahan dan keridloaan dari Allah inilah yang dinamakan manajemen syariah. (Karebet M dan Yusanto M.I, 2004)

Manajemen syariah menuntun lembaga filantropi dalam menyusun perencanaan program mulai dari perencanaan SDM, Keuangan, operasi dan pemasaran. Dalam menjalankan operasinya SMKIT menggunakan manajemen syariah sebagi mekanisme kerjanya. Hal ini dilihat dari berbagai sisi. Dalam perencanaan SDM; rekrutmen guru dan pegawai mendasarkan diri pada dasar dasar muammalah dalam Islam seperti syarat pekerja, jenis pekerjaan dan aqad kerjanya. Syarat pekerja yang bekerja di SMKIT Smart Informatika sebagai mana yang tercantum di buku panduan penegelolaan JSIT antara lain beragama Islam, tidak merokok, mampu membaca al Qur'an dan lain lain. Jenis pekerjaan yang aqadkan sesuai dengan kesepakatan di dalam aqad atau kontrak kerja. Sementara kontrak kerja disepakati atas keridloaan pekerja dan sekolah atas gaji dan pekerjaannya. Dari sisi perencanaan keuangan; keuangan sekolah diperoleh dari yayasan solopeduli atas bantuan donator sesuai dengan aqad donasi dan penyalurannya sesuai dengan syariah Islam yang mengaturnya. Misalnya kalau donasi untuk zakat maka penyalurannya atas delapan asnaf penerima zakat, ada fakir, miskin dan lain sebagainya. Ketentuan syariah senantiasa dijadikan pegangan oleh pegawai dalam pengelolaan keuangan. Demikian juga pengelolaan ditingkat sekolah, setiap rupiah yang dikucurkan oleh yayasan harus dapat dipertanggungjawabkan. Amanah inilah yang akhirnya membuat sekolah tidak bisa seenaknya membelanjakan uang sekolah tanpa pertanggungjawaban. Maka yayasan senantiasa mengontrol dan mengawasi keuangan sekolah karena semuanya merupakan amanah dari donator. Perencanaan operasional; sekolah berjalan sesuai dengan rencana sekolah yang sudah disusun di awal tahun antara sekolah dengan yayasan, rapat kerja tahuanan menjadi momentum sekolah untuk meletakan dasar pijakan program yang akan dilaksanakan warga sekolah, mulai dari jenis kegiatan hingga keuangannya.

Yayasan solopeduli yang telah mengadopsi manajemen syariah modern mampu mengawal SMKIT Smart informatika bergerak dan berjalan searah dengan kepentingan lembaga sebagai penyalur dana umat. Basis filantropi sebagai wujud kedermawanan social telah menginspirasi sekolah dalam perwujudan visi, misi dan tujuan sekolah. Bahkan dengan spirit kedermawanan dari kalangan yang mestinya disantuni inilah SMKIT Smart infromatika menjadi sekolah prestatif di Surakarta dan Jawa Tengah.

SMKIT didedikasikan untuk kaum miskin, sehingga orang kaya tidak boleh belajar di sekolah tersebut. Namun tidak hanya itu sekolah ini mampu merekrut siswa miskin yang berprestasi dan bermental baja, melalui seleksi yang begitu ketat. Peruntukan bagi siswa miskin melalui beberapa mekanisme, seperti surat keterangan tidak mampu dari pemerintah desa, rekomendasi takmir masjid terkait penghasilan orang tua siswa, survey langsung ke lokasi 
rumah calon peserta didik, dan wawancara dengan orang tua. Semua mekanisme dilalui dengan harapan bantuan dari para donasi benar benar sampai pada pihak yang membutuhkan. Dari banyaknya pelamar ke sekolah dan keterbatasan kuota atau kemampuan yayasan menyalurkan bantuan menyebabkan sekolah harus menerapkan system seleksi yang ketat. Dari mekanisme inilah diperoleh siswa yang prestasi dan bermental baja. Dan bermodal input siswa yang prestasi diimbangi dengan motivasi dan efikasi yang tinggi dari siswa akhirnya menghantarkan sekolah menuju peringkat tertinggi di kota Surakarta.

Serani (2012) pernah melakukan penelitian terhadap 62 siswa tentang perngaruh efikasi diri terhadap prestasi berdasar tipe tes pada mata pelajaran Akuntasnsi kelas XII IPS SMA N 9 Malang, kesimpulan penelitian menunjukkan bahwa efikasi yaitu keyakinan diri siswa terkait dengan dengan kemampuannya berpengaruh positif terhadap prestasinya.

Hidayat, A ( 2011) pernah melakukan penelitian terhadap siswa miskin di SMU Negeri 1 Kota Padang, dengan judul Tindakan siswa dari keluarga miskin mempertahankan prestasi di sekolah menengah umum (SMU) negeri 1 kota padang, hasilnya adalah tindakan siswa dalam mempertahankan prestasi di bagi menjadi dua; di sekolah, yaitu konsentrasi pada saat guru mengajar, meminjam buku di perpustakaan, menggunakan wifi/hotspot gratis sekolah, melakukan diskusi dengan guru, membuat catatan catatan penting (rangkuman pelajaran) sementara di rumah tindakannya adalah meminjam referensi pada alumni, mengulang pelajaran sekolah di rumah, membentuk kelompok belajar. Berdasar wawancara dengan ustadz Qosim dan pengamatan di lapangan beberapa hal di atas juga dilakukan oleh siswa SMKIT Smart Informatika.

Keberhasilan sekolah juga tidak lepas dari pengelola sekolah yang mampu menyajika program sekolah dengan baik mengemas kegiatan yang menarik dan mengoptimalkan potensi potensi yang ada. Kemandirian, keuletan dari peserta didik menjadi potensi yang cukup bagus untuk diselipkan pada setiap kegiatan sekolah. Ada hal lain yang juga tidak lepas dari filantropi sebagai ide dasar pendirian sekolah yang ternyata juga menjadi spirit dan pendorong paling dahsyat di sekolah yaitu sedekah. Menurut ustadz Qosim inilah yang menjadi kunci keberhasilan sekolah di tahun pelajaran 2014/2015 dan hal ini diamin oleh waka kurikulum. Kedermawanan siswa dibangun atas sandaran kesadaran hubungan dirinya dengan Allah swt dan diselipkan dalam kegiatan kegiatan sukses ujian nasional. Sekolah mengemasnya dengan nama program langit.

Ada beberapa hal menarik yang perlu dibahas lebih mendalam berdasar paparan data yang telah dikumpulkan oleh peneliti:

1. Sekolah meyelenggarakan kegiatan secara serius dengan spirit filantropi Islam

Berdasar pemaparan data hasil penelitian di atas mulai dari perencanaan visi, misi tujuan sekolah, rencana kegaiatan, spirit filantropi begitu Kendal dan bangunan manajemen syariah begitu kuat. Visi SMKIT Smart Informatika Surakarta digali dan diturunkan dari visi utama Yayasan Solopeduli sebagai Filantropi yaitu Menjadi SMK Gratis Percontohan dalam bidang TIK pada tahun 2015. Dan di tahun 2015 visi sekolah dirumuskan kembali oleh kepala 
sekolah yang baru (Ust Arif Priyanto SPdI) yaitu Menjadi Sekolah Gratis Percontohan yang Islami dan Berdaya saing. Karakter sebagai sekolah gratis menjadi brand image bagi SMKIT Smart informatika. Islami sebagai dasar dan kekhasan sekolah di bangun sesuai dengan standar jaringan sekolah Islam terpadu atau JSIT. Dalam buku panduan pengelolaan JSIT tecantum standar minimal serta karakter yang ingin dibentuk pada diri seorang siswa, minimal memiliki 10 karakter kepribadian seorang muslim antara lain;

a. Salimul Aqidah (aqidah yang bersih)

b. Shahihul Ibadah (ibadah yang benar)

c. Matinul Khuluq (akhlak yang mantap)

d. Qadiran ala kasbi (mandiri)

e. Mustaqqafal fikr (berpengetahuan luas)

f. qawiyyal jism (sehat)

g. Mujahidul linafsihi (mengendalikan nafsu)

h. munazzamun fi syu'unihi (mampu mengatur urusan diri)/ berjiwa pemimpin

i. haaritsan ala waqtihi (menjaga waktu/disiplin)

j. Nafi'un lighairibi (bermanfaat bagi orang lain)

Bila dikaji dari sisi manajemen sekolah maka visi ini telah mengandung nilai dan watak yang diharapkan di masa depan, memiliki keunggulan yang diinginkan masyarakat dan menjadi distingsi (pembeda) dari sekolah lain. Hal ini sebagaimana pedoman penyusunan visi menurut Beare et.al. (1993), yaitu:

a. Visi seorang pemimpin sekolah mencakup gambaran tentang masa depan sekolah yang diinginkan.

b. Visi akan membentuk pandangan pemimpin sekolah tentang apa yang menyebabkan keutamaan atau keunggulan sekolah.

c. Visi seorang pemimpin sekolah juga mencakup gambaran masa depan sekolah yang diinginkan di mata sekolah lain dan masyarakat secara umum.

d. Visi seorang pemimpin juga mencakup gambaran proses perubahan yang diinginkan berdasarkan masa depan terbaik yang hendak dicapai.

e. Masing-masing aspek visi pendidikan dalam sekolah merefleksikan asumsi-asumsi, nilainilai, dan keyakinan-keyakinan yang berbeda-beda tentang (1) watak dan sifat manusia; (2) tujuan pendidikan dalam sekolah; (3) peran pemerintah, keluarga, masyarakat terhadap pendidikan dalam sekolah; (4) pendekatan-pendekatan dalam pengajaran dan pembelajaran; dan (5) pendekatan-pendekatan terhadap manajemen perubahan.

Dalam teori manajemen rumus sederhana tentang visi dan strategi ini, yaitu SMART: Spesifik, visi harus spesifik agar strategi dapat dengan mudah dirumuskan. Meaningful, artinya visi harus sungguh-sungguh dan berarti bagi warga sekolah atau organisasi sekolah, ada juga yang mengatakan Measurable, artinya dapat diukur. Ini ada kaitannya dengan strategi, strategi yang baik harus terukur dengan jelas. Achievable, dapat dicapai.Visi yang baik adalah yang dapat diraih jadi bukan sekedar sebuah mimpi penuh ilusi namun realistic. Resourche, pada 
saat merumuskan visi dan strategi harus paham tentang sumber daya yang mendukung agar visi tersebut terwujud. Dan terakhir adalah Timeline, strategi harus mampu mengukur waktu kapan tercapai visi tersebut. Tidak abu-abu, semua harus jelas.

Visi penting bagi warga sekolah, terutama manajemen sekolah (kepala sekolah dan wakil kepala sekolah) sebagai penyususn strategi dan kebijakan sekolah. Visi bagi organisasi sekolah dapat digunakan sebagai penyatuan tujuan, arah dan sasaran sekolah, sebagai dasar pemanfatan dan alokasi sumber daya serta pengendaliannya, sebagai pembentuk dan pembangun budaya sekolah (David, 2006).

Ada tujuh elemen yang dapat digunakan untuk meningkatkan efektifitas komunikasi visi antara lain (David, 2006) :

a. Simplicity (visi sebaiknya dituliskan secara sederhana sehingga mudah dikomunikasikan kepada semua orang baik secara internal maupun secara eksternal)

b. Metaphor, analogy and example (visi dapat secara sederhana dituliskan melalui kata kata bersifat kiasan, analogi dan contoh agar visi dapat lebih mudah dikomunikasikan)

c. Multiple forum (mengkomunikasikan visi dapat dilakkan dengan berbagai forum seperti rapat dan pembicaraan informal lainnya)

d. Repetition (visi akan dapat meresap dan dipahami secara mendalam biasanya setelah diulang berkali kali)

e. Leadership by example (mengkomunikasikan visi akan lebih efektif jika tunjukkan dengan adanya kesamaan antara perkataan dan perilaku atasan)

f. Explanation of seeming inconsistencies (jika ternyata ada inkonsistensi butir di atas maka manajamen harus memberikan penjelasan seara sederhana dan jujur untuk menghindari berkurangnya kepercayaan pegawai pada manajemen)

g. Give and take (mengkomunikasikan visi akan lebih efektif apabila dilakukan dua arah)

Walau ada guru yang belum hafal dengan visi sekolah namun kebanyakan guru telah paham dengan slogan sekolah. Dalam manajemen bisnis, slogan merupakan salah satu elemen penting dalam sebuah brand, karena bisa memudahkan calon pelanggan untuk mengingat brand dari sebuah produk. Slogan bukanlah sebuah merek, tapi perpaduan komitmen dan semboyan guna terus menciptakan suatu produk yang inovatif dan unggul. Slogan yang membangun, menimbulkan citra yang baik pula bagi produk sebuah perusahaan. Slogan bila dilabelkan pada produk bermakna kualitas produk tersebut, namun jika slogan disandngkan dengan logo maka slogan menjadi media untuk mengkomunikasikan visi organisasi.

1) Kata sedekah, donasi, dhuafa dan sejenisnya dijadikan sebagai view point lembaga dalam mengorganisir pegawai, menyamakan langkah dan membangun kebersamaan serta membangun kerelaan dalam bekerja.

Dengan apa kita akan menyamakan langkah, menyamakan perasaan, dan terbangun kerelaan dan kebersamaan merupakan hal yang penting dalam organizing. Dalam kitab At takatul (2004) Asy Syekh Taqiyuddin An Nabhani menyatakan ada beberapa ikatan yang dapat menyatukan langkah, pandangan dan gerak kutlah (kelompok, organisasi atau lembaga 
termasuk sekolah), pertama ikatan kesukuan, ikatan ini muncul karena perasaan satu suku, kabilah, marga atau satu keluarga. Untuk menyatukan langkah dan berkordinasi mereka menggunakan jargon atau symbol suku kabilah, marga atau keturunannya. Ikatan ini lemah batil rusak dan merusak, berpotensi menimbulkan konflik antar suku, marga dan keluarga. Kedua ikatan nasionalisme, ikatan ini muncul karena satu bangsa dan satu Negara, maka berdirilah sekolah Indonesia di Arab, Philipine dan lain sebagainya. Ikatan ini hanya muncul ketika ada respon dari luar atau ketika berada diluar wilayah. Ketika posisi tidak seperti di atas maka ikatan ini tidak muncul. Ketiga ikatan maslahat, yaitu ikatan yang muncul ketika ada kemaslahatan bersama. Ketika ada bencana, kelaparan atau kemiskinan maka orang berbondong bondong selangkah dan seirama maju bersama ikut membantu misalnya memberi sumbangan bagi yang kaya menyumbang tenaga bagi yang tidak punya harta, menyumbangkan pemikirannya bagi yang punya keahlian. Sehingga kita bisa melihat seperti SMKIT Smart Informatika yang didirikan oleh solopeduli dan dibantu oelh para donator serta dikerjakan oleh orang orang yang ikhlas dengan dasar pertimbangan kemaslahatan. Ikatan ini cukup bagus untuk mengerakkan orang menarik orang untuk mengeluarkan dananya dan lain sebagainya. Namun sebenarnya masih ada ikatan yang lebih uat yaitu ikatan ideology, ikatan yang dibangun karena dorongan ideology yang dianutnya misalnya Islam. Ikatan ini dikatakan lebih kuat dari ikatan maslahat karena ketika maslahat sudah lewat maka ikatan itu tetap terus terjaga sehingga kelangengannya terjamin. Berpijak dari hal diatas seluruh pegawai dan karyawan SMKIT Smart informatika harus diikat dengan ikatan ideology Islam walaupun pemantiknya adalah kemaslahatan.

Meletakkan kemiskinan sebagai musuh, orang miskin harus dibantu merupakan hal yang penting bagi sebuah lembaga hal ini sebagai sarana koordinasi mengumpulkan potensi dan kekuatan. Bahkan dalam manajemen negara, kadang sebuah negara menciptakan musuh agar koordinsi internal Negara dapat berjalan dengan efektif.

Contoh lain misalnya, Badan koordinasi penanggulangan bencana nasional (indosiar, 26/02/2005) mampu mengkoordinasikan berbagai pihak terkait dengan bencana gempa aceh sehingga mendapatkan dana bantuan hingga 25 Februari 2005 mencapai Rp 432,9 miliar dari dalam neger, dan Rp 2,2 triliun dari luar negeri. Dengan mengeksploitasi kata kemiskinan Baznas dapat mengumpulkan dana sampai bulan Juni 2015 sebesar Rp 40.342.211.014.(pusat Baznas, go.id 23/10/2015)

"hingga kini, jumlah relawan yang pernah bergerak bersama Indonesia mengajar mencapai angka belasan ribu orang. Mereka hadir langsung, tak ada undangan luar biasa yang dapat perlakuak istimewa. Semua setara semua tulus, semua siap berbagi, karena semua yakin bahwa pendidikan adalah urusan bersama", itulah kata kata yang terungkap diblog Indonesia mengajar, kata dan keyakinan bahwa pendidikan adalah urusan bersama mampu mengorganizing orang dari berbagai daerah.

Kepala sekolah daam berbagai kesempatan, seperti yang terekam dalam wawancara senantiasa menggunakan kata bahwa rezeki sudah ada yang mengaturnya, bila ditempat 
ini kita tidak mendapatkan yang banyak maka diluar pasti akan mendapatkannya, kalimat kalimat yang senada inilah yang dapat menyatukan langkah, menyamakan perasaan bahwa mendidik kaum miskin adalah tugas mulia dan berpahala tinggi di sisi Allah swt. Hal inilah yang tidak banyak dimiliki oleh sekolah lain sehingga mereka merasakan kesulitan dalam menyeragamkan langkah menyatukan perasaan dan menarika keikhlasan dalam bekerja.

2) Donatur, donasi, dan Amanah para donator merupakan kata pemantik sehingga memunculkan pengawasan diri dan pengawasan ilaihi, dalam mengelola sekolah mulai dari perencanaan, pelaksanaan pelaporan dan evaluasi.

"Ini adalah uang umat, donasi dari para donator, kita harus amanah" kalimat inilah yang sering dijadikan pijakan sehingga lembaga serius dalam melakukan pengawasan, dan secara inheren kata kata tersebut menjadi intrumen pembangun rasa takut dalam diri pegawai sehingga hati hati dan bertanggung jawab dalam mengelola keuanganbaik di sekolah maupun ditingkat yayasan.

Rasa takut yang merupakan cerminan adanya amanah perlu dibangun oleh lembaga sehingga pegawai hati hati dalam mengelola keuangan, namun rasa takut harus ditanamkan secara benar. Muhammad Muhammad Isamil (2007) dalam kitab Bunga rampai pemikiran islam menyatakan bahwa ada beberapa rasa taku, pertama rasa takut yang disebabkan oleh materi atau jasadi, kedua rasa takut yang disebabkan oleh bayangan ketakutan oleh akalnya sendiri, dan ketika rasa taku pada dzat yag memang secara hakiki perlu ditakuti. Rasa takut pada materi dapat hilang ketika kita dapat memastikan bahwa ketakutan tersebut dapat dikalahkan secara konkrit entah dengan kekuatan sendiri, dengan alat atau dengan bantuan orang lain. Ketakutan yang ada dalam pikiran kita (abstrak) dapat dikalahkan atau dihilangkan ketika akal kita dapat menerima secara logis bahwa hal yang menakutkan tersebut sebenarnya tidaklah menakutkan. Ketakutan yang sejatinya kita patut takut adalah ketakutan kita pada Allah SWT. Secara dzat memang Allah layak untuk ditakuti karena adzab dan ancamannya memang menakutkan (sejatinya menakutkan). Ketika kita memiliki rasa takut seperti ini tidak mudah hilang. Maka hal inilah yang dapat dijadikan pengawasan sejati, alami dan bertahan lama dalam diri. Sudah selayaknya lembaga menanamkan rasa takut seperti ini dalam diri pengelola sekolah. Bila telah tertanam maka hal tersebut akan menjadi pengawas sendiri.

Tiga pilar pengawasan menurut manajemen syariah (Yusanto, M I dan Widjayakusuma MK, 2003), adalah:

a) Ketaqwaan individu. Seluruh personel SDM perusahaan dipastikan dan dibina agar menjadi SDM yang bertaqwa.

b) Kontrol anggota. Dengan suasana organisasi yang mencerminkan formula TEAM, maka proses keberlangsungan organisasi selalu akan mendapatkan pengawalan dari para SDMnya agar sesuai dengan arah yang telah ditetapkan.

c) Penerapan (supremasi) aturan. Organisasi ditegakkan dengan aturan main yang jelas dan transparan serta-tentu saja-tidak bertentangan dengan syariah. 
d) Sekolah dan yayasan solopeduli telah memanfaatkan peran syariah dalam pengawasan, sehingga pegawainya amanah dan keuangan transparan.

3) Sekolah mengeksplorasi sedekah, tahfidz, mentoring dan menjadikannya sebagai entri point untuk membangun kecerdasan Spiritual.

Kecerdasan Spiritual (Zohar dan Marshal, 2000) merupakan kecerdasan yang berkaitan dengan kemampuan dalam menghadap dan memecahkan persoalan makna dan nilai, menempatka perilaku hidup, menilai apakah tindakannya bermakna atau tidak dalam kehidupannya.

Program langit yang dibangun oleh sekolah, memodifikasi sedekah dengan tahfidz dan mentoring telah berhasil membangun kesadaran hubungan siswa dengan Allah, menjadikan dirinya lebih dekat dan membangun keyakinan bahwa dirinya akan dibantu oleh Allah swt. Kesadaran merupakan pintu gerbang menuju kecerdasan Spiritual. Menurut Guru spiritual (Mello, 2011) beranggaban bahwa kesadaran yang dialami jauh lebih kaya, lebih utuh dan lebih dekat dengan aslinya. Artinya sesuatu itu bermakna dan bernilai atau tidak (berguna bagi orang lain) apabila secara sadar kita menjalani, merasakan dan melihat langsung kemanfatan dan kegunaan hal tersebut. Program sedekah mampu membangun kesadaran hidup, menanamkan nilai pada siswa akan keberadaan dirinya dihadapan Allah bahwa hidup itu saling membutuhkan dan senantiasa bersandar kepada dzat yang tidak menyandarkan dirinya pada dzat lain. Linus K Palindangan (2013) menguatkan dengan menyatakan bahwa kecerdasan spiritual dapat dilatih dan dibentuk dengan membangun kesadaran, melatih kesadaran diri, kesadaran social dan kesadaran kosmis (hubungan dirinya dengan Allah SWT)

Menurut Zohar and Marshal (2000) orang yang memiliki kecerdasan spiritual cirinya; pertama, memiliki kesadaran diri, yaitu tingkat kesadaran yang tinggi dan mendalam sehingga bisa menyadari berbagai situasi yang datang dan menanggapinya. Kedua memiliki visi yaitu memiliki pemahaman tentang tujuan hidup dan memiliki kualitas hidup yang diilhami oleh visi dan nilai nilai (agama), ketiga bersikap fleksibel, mampu menyesuaikan diri secara spontan untuk mencpai hasil yang baik, memiliki pandangan pragmatis (nilai guna) dan efisien tentang realitas. Keempat berpandangan holistic yaitu memandang bahwa diri sendiri dan orang lain saling terkait dan bisa melihat keterkaitan antara berbagai hal. Kelima melakukan perubahan yaitu terbuka terhadap perbedaan, memiliki kemudahan untuk bekerja melawan konvensi dan status quo. Keenam sumber inspirasi yaitu mampu menjadi sumber inspirasi bagi orang lain. Ketujuh refleksi diri yaitu memiliki kecenderungan apakah yang mendasar dan pokok dalam hidup. Kecerdasan Spiritual (Rahmasari, 2012) berpengaruh positif terhadap kinerja seseorang. Ardana, Aritonag dan Darmawan (2013) juga mengatakan bahwa kecerdasan spiritual berkorelasi positif dengan prestasi. Penelitian ini dilakukan di Fakultas Ekonomi Universitas Taruma Negara tahun akademik 2011-2012.

Muhammad Muhammad Ismail (1997) dalam bukunya Bunga Rampai Pemikiran Islam menyatakan bahwa ada tiga kekuatan yang mendorong manusia beraktifitas, pertama 
kekuatan materi, kedua kekuatan moral dan ketiga kekuatan ruhani. Kekauatan yang paling besar adalah kekuatan ruhani, kekuatan ini dapat mengalahkan kekuatan materi, dan kekuatan moral. Kekuatan ruhani ini muncul karena adanya kesadaran hubungan dirinya dengan Allah swt. Banyak orang yang sampai merelakan harta bahkan nyawanya karena adanya keyakinan balasan yang besar disisi-Nya. Banyak orang yang bergerak dan beraktifitas walaupun dalam kehidupan yang sempit dan pas-pasan serba kekurangan financial maupun material namun hal tersebut dapat berjalan dengan baik seolah tidak ada hambatan maupun kekurangan. Inilah dahsyatnya kekuatan ruhani. Berpijak dari hal di atas tidak aneh bila sekolah ini mampu meraih peringkat satu di kota Surakarta dan peringkat lima di Provinsi Jawa Tengah. Sekolah mampu melahirkan pribadi yang memiliki 10 karakter seorang muslim sejati yang di bentuk melalui program intra maupun ekstra, di dalam sekolah maupun di asrama.

\section{Kesimpulan}

Berdasar pemaparan di atas maka dapat disimpulkan bahwa;

1. Keberadaan dan posisi Solopeduli sebagai lembaga filantropi Islam menjadikan sekolah sebagai unit programnya memiliki karakter manajemen yang khas yaitu manajemen syariah, mulai dari perencanaan, pelaksanaan, pengarahan dan pengawasan. Sekolah menyelenggarakan kegiatan secara serius dengan spirit filantropi Islam.

2. Dhuafa, keridloan dan keprihatinan serta kata sejenisnya dijadikan sebagai view point lembaga dalam mengorganisir pegawai, menyamakan langkah, membangun kebersamaan dan membangun keikhlasan dalam bekerja.

3. Donatur, donasi, dan amanah para donator merupakan kata pemantik sehingga memunculkan pengawasan diri dan pengawasan ilahi. Hal inilah yang menjadikan kegiatan berjalan secara efektif dan efisien.

4. Sekolah mengeksplorasi sedekah, tahfidz, mentoring dan menjadikannya sebagai entri point untuk membangun kecerdasan Spiritual. Sedekah, tahfidz dan mentoring merupakan program latihan untuk membangun kesadaran diri, kesadaran diri menjadi pintu gerbang menuju kecerdasan spiritual. Kecerdasan spiritual mengantarkan peserta didik menuju puncak prestasi. 


\section{Bibliografi}

Allison, M. \& Kaye, J. (2005). Strategic planning for nonprofit organizations: A practical guide and workbook (2nd ed.). Hoboken, N.J.: Wiley.

Armstrong, Scoot. J. 1983. Strategic Planning and Forecasting Fundamentals. From Kenneth Albert (ed.), the Strategic Management Handbook. New York: McGraw Hill, 1983, pp. 2-1 to 2-32.

Aan Nasrullah, 2015, Pengelolaan Dana Filantropi Untuk Pemberdayaan Pendidikan Anak Dhuafa, Jurnal Studia Islamica vol 12 No 1 Juni 2015, p 1-18

Ardana, Aritonang Dan Darmawan, 2013, Kecerdasan Intelektual, Kecerdasan Emosional, Kecerdasan Spiritual Dan Kesehatan Fisik Untuk Memprediksi Prestasi Belajar Mahasiswa Akuntansi, Jurnal Akuntansi Vol XVII, No 3 September 2013

Anonim, 2015, Putra Bogor peraih peringkat UN, di download dari http://Jakarta Bisnis com, tanggal 26 Juni 2015 jam 10.34

Anonim, 2015, Bakornas Serahkan Laporan Dana Bantuan Aceh untuk Diaudit BPK, didownload $t$ anggal 23/10/2015 dari http://www.indosiar.com/fokus/bakornasserahkan-laporan-dana-bantuan-aceh-untuk-diaudit-bpk_30108.html ， diakses tanggal 23 Oktober 2015

Anonym, 2015, Laporan Baznas, http://pusat.baznas.go.id/wp-content/uploads/ downloads/2015/08/Laporan\%20Keuangan\%20Bulanan\%20Baznas\%20Juni\%20 2015.pdf diakses tanggal 23/10/2015

Brickley, James A dan Van Horn, R Lawrence. 2000. Incentives In Nonprofit Organization: Evidence from hosfitals. William E. Simon graduate School of Business Adiministration, University of Rochecter, Rochster, NY 14627, USA

Djunaedi, Prof. Dr. Ir. Achmad. 2002. Konsep perencanaan Strategis. Program Magister Perencanaan Kota dan Daerah. Universitas Gadjah Mada.

Emzir, 2010, Analisis Data: Metodologi Penelitian Kualitatif, Rajawali Pers: Jakarta

Helming, Prof. Dr. Bernd., Jegers, Prof. Dr. Marc dan Lapsley, Prof. Dr. Irvine. 2004. "Challenges in Managing Nonprofit Organizations: A Research Overview”. Working Paper Series Nonprofit Management WP NPO No. 1: Switzerland

Hidayat A, 2011, Tindakan Siswa Dari Keluarga Miskin Dalam Mempertahankan Prestasi Di SMU Negeri 1 Kota Padang, Skripsi: Universitas Andalas Padang.

Hilman Latif, 2012, Filantropi Islam dan Aktivisme Sosial Berbasis Pesantren di Pedesaan, Jurnal Afkaruna, vol 2 no 8 tahun 2012 
Hospt, Klaus J. April 2009. The Board of Nonprofit Organizations: Some Corporate Governance Thoughts from Europe. Max Planck Institute of Foreign Private and Private International Law Mittelweg 187 D-20148 Hamburg, Germany

Howell, R. A. (2004). Turn your budgeting process upside down. Harvard Business Review, 82(7), 21-22. . Retrieved from http://ezproxy.library.dal.ca/login?url=http://search. ebscohost.com/login.aspx?direct=true \&db=bth\&AN=13620529\&site=ehost-live

Ismail, MM, 1997, Bunga Rampai Pemikira Islam, Gema Insani Pers Jakarta

Imron Hadi Tami, 2011, Peran Filantropi Dalam Pengentasan Kemiskinan Di Dalam Komunitas Local, Jurnal Sosiologi Islam, Vol 1 No 1 April 2011

Krishan, ranjani, Yetman, Michelle H dan Yetman, Robert. Financial Disclosure management by nonprofit organization. Eli Broad College of Business, Michigan State University, East Lansing, MI 48824. Tippie College of Business, the University of Iowa, Iowa City, IA 52240 .

Kholis, Nur and Sobaya, (2013): Potret Filantropi Islam Di Daerah Istimewa Yogyakarta. La_ Riba: Jurnal Ekonomi Islam, Vol. 1, No. 7 (31. July 2013): pp. 61-84.

Lia Yuliana Dan Suharsimi Arikunto, 2008, Manajemen Pendidikan, Aditya Media Yogyakarta

Moleong, Lexy J, 2011, Metodologi Penelitian Kualitatif Edisi Revisi, Remaja Rosda Karya: Bandung

Molle, 2011, Butir Butir Pencerahan, Gramedia Jakarta

Palindangan LK, 2013, Jurnal administrasi dan kesekretariatan, vol 5 nomor 1 Maret 2013

Pearce II and Robinson Jr, 2013, Manajemen Strategis, Salemba Empat: Jakarta

Rahmasari Lisda, 2012, Pengaruh Kecerdasan Intelektual, Emosional dan kecerdasan Spiritual terhadap kinerja karyawan, Jurnal majalah Informatika Vol 3 No 1 Januari 2012

Resi Anggun Sutiasnah, 2015, faktor-faktor penyebab anak putus sekolah, Jom Fisip, Vol 2 No 1 1 Februari 2015

Anonim, 2008, Strategic planning (in nonprofit or for-profit organizations). Retrieved 5/14/2008, http://www.managementhelp.org/plan_dec/str_plan/str_plan.htm\#anchor320170

Serani, Elsmeyti Indra. 2012. Pengaruh Efikasi Diri Siswa terhadap Prestasi Belajar berdasarkan Tipe Tes pada Mata Pelajaran Akuntansi Kelas XI IPS SMA Negeri 9 Malang. Skripsi, Jurusan Pendidikan Akuntansi Fakultas Ekonomi Universitas Negeri Malang.

Sutrisni's, Adi.2009. Perencanaan Strategis bagi Organisasi Sosial, http://sirtus.multiply.com/ journal/item/6/

Tom, H. B. (2008). Thinkingstrategically firstmakesstrategic planningwork. Retrieved May29, 2008, from http://humanresources.about.com/od/strategicplanning1/a/thinking_plan.htm 
128 | Joko Subando

Widjajakusuma M.K dan Yusanto M.I, 2003, Pengantar Manajemen Syariat, Khairul Bayan: Jakarta

Widjajakusuma, Muhammad Karebet. 2005. Konsep Manajemen strategi dan implementasinya dalam Pengelolaan Organisasi nirlaba persfektif Syariah. SEM Institute Jakarta

Yusanto, M I dan MK, Widjayakusuma, 2003, Manajemen Strategis Perspektif Syariah, Khairul Bayan: Jakarta

Zohar, D and Marshall, I, 2000, Spiritual Intelegence the Ultimate Intelligence, Bloomsbery: Great Britain. 